\title{
REGEPE

\section{COMPORTAMENTO E POTENCIAL EMPREENDEDOR À LUZ DA ESCALA DE CARLAND ENTREPRENEURSHIP INDEX (CEI), NA ÓTICA DE ESTUDANTE UNIVERSITÁRIOS}

\author{
1 Marta Elisa Morais da Silva Bendor \\ 2 Fernando Cesar Lenzi \\ 3 Antônia Marcia Rodrigues Sousa
}

\section{Resumo}

Objetivo: analisar a contribuição do ensino de empreendedorismo para o desenvolvimento do potencial empreendedor dos estudantes de Administração de uma Instituição de Ensino Superior.

Método: o estudo foi dividido em duas etapas: (1) uma pesquisa descritiva e documental, com abordagem qualitativa; e (2) um estudo quantitativo, por meio de uma survey. O instrumento de coleta de dados utilizado foi proposto por Carland, Carland e Hoy (1992), denominado de Carland Entrepreneurship Index (CEI).

Originalidade/Relevância: a pesquisa aprofunda a discussão acerca do potencial empreendedor e do ensino de empreendedorismo, no âmbito da Educação Superior, evidenciando fatores empíricos decisivos para a formação de novos gestores empreendedores.

Resultados: os mecanismos metodológicos mostraram a existência de conhecimentos congruentes entre o modelo testado e os conteúdos disseminados em sala de aula, evidenciando, com isso, a contribuição para a formação empreendedora dos estudantes, nos quesitos decrescentes de identificação de potencial empreendedor, tanto para micro quanto para macroempreendedores.

Contribuições teóricas/metodológicas: o estudo contribui com a literatura, ao sinalizar, por meio das proposições empíricas, que a integralização de conteúdos, no processo da formação do estudante, exerce uma função balizadora na construção de comportamentos voltados à educação empreendedora.

Contribuições sociais/para a gestão: os achados em campo foram salutares ao direcionamento da gestão pedagógica e da equipe docente, no que diz respeito à interdisciplinaridade de conteúdos de formação empreendedora, nos núcleos de formação básica, complementar e no conteúdo dos estudos quantitativos e de suas tecnologias, conforme as Diretrizes Curriculares Nacionais do curso de Graduação em Administração.

Palavras-chave: Empreendedorismo. Ensino de empreendedorismo. Potencial empreendedor.

Recebido: 03/06/2019 / Aprovado: 08/01/2020

Editor responsável: Profa. Dra. Vânia Maria Nassif

Processo de avaliação: Double Blind Review

Doi: https://doi.org/10.14211/regepe.v9i3.1636

\footnotetext{
${ }^{1}$ Centro Universitário - UNINTA, São Paulo, (Brasil). E-mail: martabendor@gmail.com Orcid id: https://orcid.org/0000-0001-8790-136X

${ }^{2}$ Universidade do Vale do Itajaí - UNIVALI, Santa Catarina, (Brasil). E-mail: lenzi@univali.br Orcid id: https://orcid.org/0000-0001-8558-0793

3Universidade Federal do Mato Grosso do Sul - UFMS, Mato Grosso do Sul, (Brasil). E-mail:pesquisadoramarciarodrigues@gmail.com Orcid id: https://orcid.org/0000-0003-0659-9897
} 


\title{
BEHAVIOR AND ENTREPRENEURIAL POTENTIAL IN THE LIGTH OF THE CARLAND ENTREPRENEURSHIP INDEX - CEI IN THE UNIVERSITY STUDENT PERSPECTIVE
}

\begin{abstract}
Objective: To analyze the contribution of the teaching of entrepreneurship, in the development of the entrepreneurial potential of Business Administration majors on a higher level education institution.

Method: The study was divided in two stages: in the first stage, a descriptive and documentary research was carried out, with a qualitative approach. Subsequently, a quantitative study was carried out by means of a survey. The data collection instrument used was proposed by Carland, Carland and Hoy (1992), called Carland Entrepreneurship Index (CEI).
\end{abstract}

Originality/Relevance: The research deepens a discussion about the entrepreneurial potential and teaching of entrepreneurship in higher education, evidencing decisive empirical factors for the formation of new managers-entrepreneurs.

Results: The methodological mechanisms demonstrated the existence of congruent knowledge between the tested model and the contents disseminated in the classroom. Thus, the contribution to the entrepreneurial training of students in the decreasing requirements of identification of entrepreneurial potential, micro-entrepreneurs and macro-entrepreneurs.

Theoretical / methodological contributions: The study contributes to the literature by pointing out, through the empirical propositions, that the content in the student training process exerts a guiding function in the construction of behaviors aimed at entrepreneurial education.

Social/management contributions: The findings in the field were salutary to direct the pedagogical management and the teaching staff regarding the interdisciplinarity of contents of entrepreneurial training in the nuclei of basic training, complementary, Contents of Quantitative Studies and their Technologies and Complementary Training Contents, as established by the National Curricular Guidelines of the Graduate Program in Administration.

Keywords: Entrepreneurship. Teaching of entrepreneurship. Entrepreneurial potential. 


\section{COMPORTAMENTO Y POTENCIAL EMPREENDEDOR A LA LUZ DE LA ESCALA DE CARLAND ENTREPRENEURSHIP INDEX (CEI), EM LA ÓPTICA DE ESTUDIANTES UNIVERSITARIOS}

\section{Resumén}

Objetivo: analizar la contribución de la enseñanza del espíritu empresarial, en el desarrollo del potencial emprendedor de los estudiantes del curso de administración, de una institución de enseñanza superior.

Método: el estudio se dividió en dos etapas: en la primera etapa se realizó una investigación descriptiva y documental, con abordaje cualitativo. En consecuencia, se realizó un estudio cuantitativo a través de una encuesta. El instrumento de recolección de datos utilizado fue propuesto por Carland, Carland y Hoy (1992), denominado Carland Entrepreneurship Index (CEI).

Originalidad/Relevancia: la investigación profundiza una discusión acerca del potencial emprendedor y enseñanza de emprendedorismo en el ámbito de la educación superior, evidenciando factores empíricos decisivos para la formación de nuevos gestoresemprendedores.

Resultados: los mecanismos metodológicos mostraron la existencia de conocimientos congruentes entre el modelo probado y los contenidos diseminados en el aula. De esta forma, la contribución a la formación emprendedora de los estudiantes en las cuestiones decrecientes de identificación de potencial emprendedor, micro emprendedores y macro emprendedores.

Contribuciones sociales/para la gestión: los hallazgos en campo fueron saludables para dirigir la gestión pedagógica y el equipo docente en cuanto a la interdisciplinaridad de contenidos de formación emprendedora en los núcleos de formación básica, complementaria, Contenidos de Estudios Cuantitativos y sus Tecnología y Contenidos de Formación Complementar, según establece las Directrices Curriculares Nacionales del Curso de Graduación en Administración.

Palabras clave: Emprendedor. Enseñanza de emprendimiento. Potencial emprendedor. 


\section{INTRODUÇÃO}

Estudos sobre a contribuição do empreendedorismo para o crescimento e o desenvolvimento econômico demonstram como positiva a influência da cultura empreendedora nesse processo, dentro da sociedade. No entanto, para gerar essa contribuição, os empreendedores enfrentam desafios que precisam ser explorados como oportunidade, transformando o ato de empreender em geração de resultados concretos, com disciplina e persistência (Schumpeter, 1934; McClelland, 1972; Carree \& Thurik, 2003; Hisrich, Peters, \& Shepherd, 2014).

Com intuito de capacitar os indivíduos para empreender, no que diz respeito à percepção de oportunidades, à geração de ideias e ao enfrentamento de desafios, o ensino de empreendedorismo constitui-se um forte aliado, já que, cada vez mais os estudantes buscam a capacitação necessária, nas mais diversas áreas de conhecimento, para se tornarem empreendedores (Hecke, 2011; Lima, Hashimoto, Melhado, \& Rocha, 2014; Rocha \& Freitas, 2014).

E vale ressaltar que, mesmo contando com uma preparação adequada, empreender é um processo por demais complexo, baseado em múltiplas variáveis, sendo essencial uma postura inovadora na utilização de determinada estratégia para desenvolver um negócio, com fins de crescimento e consequente lucro. Dessa forma, considerando que o nível de empreendedorismo se constitui uma variável subjetiva, torna-se difícil estabelecer uma ferramenta para quantificar o nível de empreendedorismo dos indivíduos (Inácio Júnior \& Gimenez, 2004).

Dentre os métodos existentes, destaca-se o Carland Entrepreneurship Index (CEI), de Carland, Carland e Hoy (1992), pelo qual o empreendedorismo se dá em função de quatro elementos fundamentais: postura estratégica, propensão à inovação, traços de personalidade (que envolvem a necessidade de realização e de criatividade) e a propensão ao risco. Conforme a presença desses elementos, os indivíduos são classificados em três categorias: microempreendedor, empreendedor e macroempreendedor, conforme a (Inácio Júnior \& Gimenez, 2004).

Diante da necessidade de formação de atuais e de futuros empreendedores, visto que esse conhecimento contribui com a economia e para o desenvolvimento da cidadania, as Instituições de Ensino Superior (IES), em seus cursos de Administração, assumem papel fundamental, pois provêm espaços de encontro entre a oferta e a demanda de conteúdos estimuladores das competências 
empreendedoras (Henrique \& Cunha, 2008; Andreassi \& Fernandes, 2010; Silva, 2010; Ribeiro \& Bernardes, 2014).

Johan, Krüger e Minello (2018) afirmam que o empreendedor é simplesmente alguém talhado para o empreendedorismo, ou seja, dotado de um leque de características passíveis de ser aprendidas. Isso evidencia, pois, que a formação de empreendedores é fator preponderante para o desenvolvimento econômico de uma região.

Considerando a característica multidisciplinar da formação empreendedora, para que seus diferentes objetivos sejam alcançados, é necessário estabelecer um plano, que adapte a metodologia de ensino ao contexto da aprendizagem esperada. Sob essa ótica, diferentes opções de métodos, de técnicas e de recursos são encontradas na literatura como forma de se promover o processo de ensinoaprendizagem do empreendedorismo (Boyles, 2012; Honig, 2004; Kuratko, 2005; Degen, 2009; Ilander, 2010; Knotts, 2011; Schmidt, Soper, \& Facca, 2012).

Sendo assim, este estudo questiona: Qual a contribuição do ensino de empreendedorismo para o desenvolvimento do potencial empreendedor dos estudantes do curso de Administração de uma Instituição de Ensino Superior, sob a ótica do Carland Entrepreneurship Index (CEI)? Para chegar a uma resposta, tem-se como objetivo principal analisar, em duas etapas, a contribuição do ensino de empreendedorismo no desenvolvimento do potencial empreendedor dos graduandos de Administração: (1) uma pesquisa descritiva e documental, de abordagem qualitativa; (2) e uma abordagem quantitativa, pelo uso da estratégia survey, com aplicação de questionários junto a uma amostra de 171 discentes do curso de Administração de uma IES no interior do Ceará. Para tanto, foi utilizada a técnica estatística de Análise de Variância (Anova), que é descritiva.

Este estudo contribui com a literatura, pois sinaliza, por meio das proposições empíricas, que a integralização de conteúdo ao processo de formação do estudante, exerce uma função balizadora na construção de comportamentos voltados à educação empreendedora. Em complemento, ele possibilita mudanças nas grades curriculares, a fim de oportunizar direcionamentos aos cursos universitários, em relação a experiências favorecedoras da formação de novos empreendedores, por meio da oferta de conteúdos e de práticas estimuladoras do desenvolvimento de competências empreendedoras (Hecke, 2011; Ribeiro \& Bernardes, 2014). Além da formação, faz-se necessário compreender os aspectos inerentes ao indivíduo, isto é, 
que ele carrega consigo, como o potencial empreendedor que, conforme Carland e Carland (1996), pode ser desenvolvido, a fim de que ele se torna capaz de identificar oportunidades e de fazer uso de sua criatividade para transformá-las em negócios, assumindo riscos para a obtenção do sucesso.

Este artigo está assim estruturado: referencial teórico sobre o ensino de empreendedorismo e o potencial empreendedor; descrição dos procedimentos metodológicos; discussão acerca dos resultados; e considerações finais, nas quais estão indicadas as limitações do estudo e as sugestões para futuras pesquisas. Com o propósito de discutir o arcabouço de teorias fundamentais ao assunto e suas contribuições relevantes, o referencial teórico é apresentado a seguir, iniciando pelo ensino de empreendedorismo, seguido do potencial empreendedor e dos desdobramentos do estudo de Carland et al. (1992), com seu modelo conceitual de classificação do empreendedor em categorias - o método CEI.

\section{ENSINO DE EMPREENDEDORISMO}

A atividade de ensino, por sua natureza de lógica não linear, no que diz respeito ao processo de ensinar e de aprender, requer práticas pedagógicas condizentes, que acompanhem as mudanças na sociedade e no perfil do aluno. Para tanto, o docente precisa estar cada vez mais qualificado perante o enfrentamento das exigências oriundas do exercício da sua profissão (Franco, 2015; Nunes \& Oliveira, 2017).

Com relação ao Ensino Superior, sua essência está na intermediação para a construção e a disseminação de conhecimentos; por isso, sua importância para a sociedade. O crescimento, portanto, deve ser o principal paradigma a ser seguido pela academia. Nesse sentido, é necessário buscar um desenvolvimento baseado nas forças produtivas, nas capacidades e na competitividade dos indivíduos, a serviço da dignidade do ser humano (Bernheim \& Chauí, 2008).

Alinhado a essa concepção, o aprendizado do empreendedorismo, para os estudantes de Administração, apresenta-se como forma de contribuir com a economia e com a constituição da cidadania. Além disso, a dificuldade de obter um emprego formal, a necessidade de desenvolver competências e habilidades, o aumento no volume de horas trabalhadas nas grandes corporações, e a busca por melhor qualidade de vida contribuíram para os indivíduos enxergarem o 
empreendedorismo como uma alternativa de carreira (Henrique \& Cunha, 2008; Andreassi \& Fernandes, 2010).

O ensino de empreendedorismo pressupõe a vivência, a adaptação e a experimentação, de forma que o aluno seja inserido em contextos reais, a fim de que ele compreenda a dinâmica de um empreendimento e esteja preparado para vivenciar as diversas situações cotidianas que lhe forem apresentarem. Em outras palavras, é preciso conceber o ensino de empreendedorismo como um processo desenvolvedor de um conjunto de práticas, cujo domínio certificará a capacidade dos discentes de pensar e de se comportar de forma empreendedora (Neck \& Greene, 2011; Neck, Greene, \& Brush, 2015)

Nesse sentido, alguns métodos, que privilegiam a prática, enquanto metodologia de ensino, como os estudos de caso e os jogos empresariais, são indicados, além de palestras, leituras, visitas a empresas, simulações, bem como realização de projetos, de planos de negócios, de vivências com empreendedores, entre outros (Filion, 2000; Honig, 2004; Souza, Souza, Assis, \& Zerbini, 2004; Kuratko, 2005; Henrique \& Cunha, 2008; Degen, 2009; Greatti, Gralik, Vieira, \& Sela, 2010; Ilander, 2010; Lopes, 2010; Knotts, 2011; Boyles, 2012; Schmidt et al., 2012; Rocha \& Freitas, 2014). Visando organizar e prover as metodologias e as aplicações pedagógicas mais adequadas ao ensino do empreendedorismo, Rocha e Freitas (2014) indicam uma lista com as principais atividades educacionais de formação em empreendedorismo (AEFE) e suas respectivas aplicações (Figura 1).

\begin{tabular}{|l|l|}
\hline \multicolumn{1}{|c|}{$\begin{array}{c}\text { Métodos, Técnicas e } \\
\text { Recursos }\end{array}$} & \multicolumn{1}{|c|}{ Aplicação } \\
\hline Aulas expositivas & $\begin{array}{l}\text { Transferir conhecimentos sobre o Empreendedorismo, as características } \\
\text { pessoais do empreendedor, os processos de inovação, as fontes de } \\
\text { recursos, os financiamentos e os aspectos legais de pequenas } \\
\text { empresas. }\end{array}$ \\
\hline $\begin{array}{l}\text { Visitas e contatos com } \\
\text { empresas }\end{array}$ & $\begin{array}{l}\text { Estimular o network e incitar o estudante a sair dos limites da IES, para } \\
\text { entender o funcionamento de mercado na realidade; desenvolver visão } \\
\text { de mercado. }\end{array}$ \\
\hline Plano de negócios & $\begin{array}{l}\text { Desenvolver as habilidades de (a) planejamento, estratégia, marketing, } \\
\text { contabilidade, recursos humanos e comercialização; (b) avaliação do } \\
\text { novo negócio, analisando o impacto da inovação no novo produto ou } \\
\text { serviço; e (c) construir habilidade de avaliar e de dimensionar riscos do } \\
\text { negócio pretendido. }\end{array}$ \\
\hline Estudo de casos & $\begin{array}{l}\text { Construção da habilidade de pensamento crítico e de avaliação de } \\
\text { cenários e negócios. Desenvolver a habilidade de interpretação e de } \\
\text { definição de contextos associados ao empreendedorismo. }\end{array}$ \\
\hline Trabalhos teóricos em & $\begin{array}{l}\text { Desenvolver as habilidades de: aprender coletivamente, pesquisar, } \\
\text { dialogar, integrar, construir conhecimentos, buscar soluções e emitir }\end{array}$ \\
\hline
\end{tabular}

Rev. de Empreendedorismo e Gest. Pequenas Empres. | São Paulo, v.9 | n.3 | p. 272-302 | Maio/Ago. 2020. 


\begin{tabular}{|c|c|}
\hline grupo & juízos de valor na realização do documento escrito. \\
\hline $\begin{array}{l}\text { Trabalhos práticos em } \\
\text { grupo }\end{array}$ & $\begin{array}{l}\text { Construção das habilidades de: atuar em equipe, planejar, dividir e } \\
\text { executar tarefas em grupo, passar e receber críticas construtivas e } \\
\text { ampliar a integração entre o saber e o fazer. }\end{array}$ \\
\hline Grupos de discussão & $\begin{array}{l}\text { Desenvolver: a habilidade de testar novas ideias; e a capacidade de } \\
\text { avaliar mudanças e de prospectá-las como fontes de oportunidades. }\end{array}$ \\
\hline Brainstorming & $\begin{array}{l}\text { Construção das habilidades de: conceber ideias; prospectar } \\
\text { oportunidades, reconhecendo-as como empreendedoras; e estimular o } \\
\text { raciocínio intuitivo, para a criação de novas combinações de serviços ou } \\
\text { de produtos, transformando-as em inovações. }\end{array}$ \\
\hline $\begin{array}{l}\text { Seminários e palestras } \\
\text { com empreendedores }\end{array}$ & $\begin{array}{l}\text { Transferir conhecimentos das experiências vividas por empreendedores } \\
\text { com: a percepção e a criação do produto, a abertura do negócio, e os } \\
\text { sucessos e os fracassos ocorridos na trajetória empreendedora. }\end{array}$ \\
\hline Criação de empresa & $\begin{array}{l}\text { Transpor as informações do plano de negócios e estruturar os contextos } \\
\text { necessários à formalização; compreender as várias etapas da evolução } \\
\text { da empresa; e desenvolver a habilidade de organização e de } \\
\text { planejamento operacional. }\end{array}$ \\
\hline $\begin{array}{l}\text { Aplicação de provas } \\
\text { dissertativas }\end{array}$ & $\begin{array}{l}\text { Testar os conhecimentos teóricos dos estudantes e sua habilidade de } \\
\text { comunicação escrita. }\end{array}$ \\
\hline $\begin{array}{l}\text { Atendimento } \\
\text { individualizado }\end{array}$ & $\begin{array}{l}\text { Desenvolver as habilidades de: comunicação, interpretação, iniciativa e } \\
\text { resolubilidade; aproximar o estudante do cotidiano real vivido nos } \\
\text { pequenos negócios. }\end{array}$ \\
\hline $\begin{array}{l}\text { Trabalhos teóricos } \\
\text { individuais }\end{array}$ & $\begin{array}{l}\text { Construção da habilidade de geração de conhecimento individualizado, } \\
\text { estimulando a autoaprendizagem; indução ao processo de } \\
\text { autoaprendizagem. }\end{array}$ \\
\hline $\begin{array}{l}\text { Trabalhos práticos } \\
\text { individuais }\end{array}$ & $\begin{array}{l}\text { Construção da habilidade da aplicação dos conhecimentos teóricos } \\
\text { individuais, estimulando a autoaprendizagem; estímulo à capacidade } \\
\text { laboral e de autorrealização. }\end{array}$ \\
\hline Criação de produto & $\begin{array}{l}\text { Desenvolver habilidades de: criatividade, persistência, inovação e senso } \\
\text { de avaliação. }\end{array}$ \\
\hline Filmes e vídeos & $\begin{array}{l}\text { Desenvolver a habilidade do pensamento crítico e analítico, associando } \\
\text { o contexto assistido com o conhecimento teórico; estimular a discussão } \\
\text { em grupo e o debate de ideias. }\end{array}$ \\
\hline $\begin{array}{l}\text { Jogos de empresas e } \\
\text { simulações }\end{array}$ & $\begin{array}{l}\text { Desenvolver as habilidades de: criar estratégias de negócios, solucionar } \\
\text { problemas, trabalhar e tomar decisões sob pressão, aprender pelos } \\
\text { próprios erros; tolerar o risco; pensar de forma analítica; comunicar-se } \\
\text { de modo intra e intergrupal. }\end{array}$ \\
\hline Sugestão de leituras & $\begin{array}{l}\text { Prover ao estudante teorias e conceitos sobre o empreendedorismo; e } \\
\text { aumentar a conscientização do ato empreendedor. }\end{array}$ \\
\hline Incubadoras & $\begin{array}{l}\text { Proporcionar ao estudante espaço de motivação e de criação da nova } \\
\text { empresa, desenvolvendo múltiplas competências, tais como: habilidades } \\
\text { de liderança, organizacionais, tomada de decisão e compreensão das } \\
\text { etapas do ciclo de vida das empresas. Estimular o fortalecimento do } \\
\text { network com financiadores, fornecedores e clientes. }\end{array}$ \\
\hline $\begin{array}{l}\text { Competição de planos } \\
\text { de negócios }\end{array}$ & $\begin{array}{l}\text { Desenvolver: habilidades de comunicação, persuasão e estratégia; a } \\
\text { capacidade de observação, percepção e aplicação de melhorias no } \\
\text { padrão de qualidade dos planos apresentados. Estimular a abertura de } \\
\text { empresas mediante os planos vencedores. }\end{array}$ \\
\hline
\end{tabular}

Figura 1. Atividades educacionais de formação em empreendedorismo Fonte: Rocha e Freitas (2014). 
A partir da Figura 1, percebe-se que as atividades descritas têm o intuito de possibilitar aos alunos - considerados empreendedores potenciais - 0 aprendizado, por meio da experimentação e de relacionamentos prático-teóricos.

Assim, com relação ao ensino de empreendedorismo nas IES, Machado, Lenzi e Manthey (2018) destacam que essas instituições devem atuar como espaços de disseminação de conhecimento, com amparo científico e tecnológico centrado na formação profissional do empreendedor, incentivando, com isso, os discentes a despertarem para o empreendedorismo e a exploração de oportunidades.

Há, portanto, uma série de desafios que as IES e o mercado devem enfrentar para o ensino do empreendedorismo (Hashimoto \& Fonseca Jr., 2018). Entre eles, está a necessidade de inovar o ensino e as etapas do aprendizado, pelo uso de uma abordagem que possibilite ao discente compreender contextos e estruturar um processo evolutivo do negócio e de suas implicações. Acerca disso, Hashimoto, Krakauer e Cardoso (2018) advogam pela utilização de atividades práticas na formação de empreendedores, por intermédio de distintas formas metodológicas. As escolas híbridas, cujos métodos abarcam tanto o ensino tradicional quanto 0 inovador, podem promover um modelo de ensino e de aprendizagem que combine prática e teoria, de modo que a vivência desenvolva e capacite o empreendedor.

Considerando a necessidade de uma abordagem multidisciplinar, imposta pelo empreendedorismo, as metodologias e suas respectivas aplicações pedagógicas devem ser reorganizadas. Em virtude disso e das propostas pedagógicas constantes na literatura científica, é preciso relacionar e descrever as aplicações dos principais métodos, técnicas e recursos utilizados no ensino do empreendedorismo. Essa ação visa fomentar o desenvolvimento de características de intenção, de potencial e de competências empreendedoras nos discentes, para que eles possam, futuramente, tornar-se agentes empreendedores.

\section{POTENCIAL EMPREENDEDOR}

O tema do empreendedorismo apresenta ampla difusão no ambiente acadêmico, constituindo-se como objeto de estudo de livros, artigos e publicações diversas. Por conta disso, várias escalas já foram elaboradas, envolvendo a aplicação de testes, para identificar e mensurar "quem é o empreendedor?" (Gartner, 1989; Carland et al., 1998; Veit \& Gonçalves Filho, 2007; Santos, 2008; Santos, Caetano, \& Curral, 2010). 
A escala de Veit \& Gonçalves Filho (2007), por exemplo, depois de testes realizados por uma survey, com 965 pequenos empresários brasileiros, teve seus resultados comparados a trabalhos anteriores, o que comprovou seu alinhamento e a tornou válida.

Para a elaboração do instrumento, os pesquisadores fundamentaram-se nos estudos de McClelland (1972); Schumpeter (1934); Timmons (1989); Carland e Carland (1996); Filion (2000); Mintzberg \& Quinn (2001); Drucker (1986), bem como em pesquisas, intermediadas pelo Sebrae e GEM, junto a empresários e a empreendedores, com base nos construtos: risco, competência estratégica, pensamento analítico, relacionamento, planejamento formal, desafio, inovação e dedicação.

Destaca-se, também, a escala Santos (2008), para medir o potencial empreendedor dos indivíduos, construída a partir de técnicas psicométricas e estatísticas, cuja aplicação pode ser feita junto a estudantes, empresários e candidatos ao ingresso em programas de incubadoras de empresas. Para a sua elaboração, foram definidos, primeiramente, os cenários; os fatores; os construtos: realização, planejamento (resolução de problemas) e poder (influência/relação com as pessoas); e os itens que, posteriormente, formaram um questionário, refinado junto a estudantes de quatro estados do país, professores de empreendedorismo e grupos de empreendedores bem-sucedidos e que fracassaram em seus negócios. Após diversos estágios de aprimoramento do instrumento, a versão final, formada por 59 questões, que utilizavam uma escala de diferencial semântico (do desnecessário ao essencial), foi validada por 100 empresários alagoanos.

Por meio dessa escala, de Santos (2008), é gerado um gráfico radial para plotagem dos pontos obtidos, com fins de comparação dos resultados entre os indivíduos não empreendedores e os empreendedores de sucesso, permitindo conhecer os aspectos que necessitam de aprimoramento. Objetivando também conhecer e medir o potencial empreendedor do sujeito que empreende, Santos et al. (2010) realizaram, em Portugal, um estudo voltado às atitudes dos universitários, em relação ao empreendedorismo. O modelo teórico proposto foi construído com base na revisão da literatura sobre o assunto, e fundamentado nos principais aspectos distintivos do comportamento empreendedor, que são: motivações empreendedoras, competências psicológicas, competências sociais e competências de gestão. 
Realizado o processo de construção conceitual, o construto de potencial empreendedor foi elaborado por meio do Inventário de Avaliação do Potencial Empreendedor (IAPE), instrumento composto por um conjunto de itens, medidos em uma escala de concordância de cinco pontos, validado junto a uma amostra de 521 universitários das áreas de Ciências Sociais, Saúde, Gestão e Tecnologia.

Ancorado no IAPE, foi construído, então, o Índice do Potencial Empreendedor (IPE), por meio da ponderação das quatro grandezas anteriormente mencionadas: motivações empreendedoras, competências de gestão, competências psicológicas e competências sociais. Tal índice é indicado para o trabalho junto às universidades e demais programas de desenvolvimento de empreendedorismo, visto que ele possibilita o posicionamento do indivíduo em uma escala de medida do seu potencial, segundo um arcabouço teórico consistente, e também identifica as competências que necessitam de ser desenvolvidas (Santos et al., 2010).

Buscando uma melhor compreensão do tema, Ferreira, Alcântara e Freitas (2013) validaram uma escala de mensuração do potencial empreendedor junto a alunos de uma IES pública. O instrumento contava com um questionário composto por 30 itens, em escala Likert, sendo os fatores analisados: planejamento, metas e controle, intenção de empreender, persistência, oportunidade, persuasão, eficiência e informações. Para a sua elaboração, os pesquisadores tomaram por base o trabalho de Santos (2008), e encontraram similaridades relacionadas aos itens "informações" e "eficiência".

Com relação ao potencial empreendedor de empresários já estabelecidos, Souza, Trindade, Freire e Lyra (2016) analisaram proprietárias de 35 empresas do setor turístico de Florianópolis (SC), por meio de um estudo descritivo, realizado por meio da aplicação da escala CEl, instrumento elaborado por Carland et al. (1992). Os resultados obtidos demonstram que $68 \%$ das entrevistadas foram classificadas como empreendedoras, haja vista a média de 19,9 apresentada, em uma escala com o máximo de 33 pontos, havendo diferenças estatísticas significativas nos fatores "traços de personalidade", "postura estratégica" e "propensão ao risco".

Nota-se, portanto, que a necessidade de compreensão do perfil do empreendedor já foi motivo de questionamentos anteriores, por parte dos pesquisadores. Durante algum tempo, os estudos no campo do empreendedorismo estiveram voltados para a pergunta: quem é o empreendedor? (Carland et al., 1998; Gartner, 1989). Nesse sentindo, busca-se considerar os aspectos essenciais ao 
desenvolvimento da ação empreendedora, como a inovação - prática sem a qual não existem empreendedores, e que não viabiliza a oportunidade de criar empresas, cujos riscos podem ser devidamente calculados, em função do ambiente onde estão inseridas. Assim, Fonseca Júnior \& Hashimoto (2014), ao analisarem o conceito de empreendedorismo, em seu sentido amplo, descrevem os empreendedores como agentes que influenciam, de modo criativo, a geração de riqueza de uma nação, sendo as bases do empreendedorismo a percepção e a exploração de novas oportunidades, no âmbito dos negócios, por meio da utilização de recursos de maneira inovadora.

Nos estudos de empreendedorismo, alguns autores, como Culti-Gimenez, Costa, Schypula, \& Gimenez (2006), consideram os indivíduos prontos ao estímulo para a geração de novos valores, dada à condição de empreendedores natos. Em virtude disso, Carland et al. (1992) propuseram um modelo conceitual, com fins de afirmar que todos os indivíduos podem ser classificados como empreendedores, categorizados de acordo com a intensidade dessa condição - o método CEI (adotado por este estudo como referência de quantificação).

A taxonomia de classificação dos empreendedores, conforme o instrumento de mensuração do potencial empreendedor, denominado Carland Entrepreneurship Index (CEI), que se baseia nos objetivos esperados para o negócio. Essa escala se pauta na constatação da presença de determinadas características nos sujeitos empreendedores; e de acordo com a sua intensidade, pode haver três grupos: microempreendedores, empreendedores e macroempreendedores.

Segundo Carland e Carland (1996), o instrumento, inicialmente, incluiu 40 questões de escolha forçada; no entanto, as questões e seus construtos evoluíram, a partir dos seguintes elementos de empreendedorismo adotados na literatura: traços de personalidade, propensão à inovação, propensão ao risco e postura estratégica; resultando na escala atual, com 33 pares de questões. Para os autores, o formato de escolha forçada resultaria em um instrumento que não exigiria treinamento, por parte do respondente, para definir sua resposta, e que, com isso, facilmente se produziria um escore numérico.

$\mathrm{O}$ intuito dos criadores do $\mathrm{CEI}$, portanto, era conceber um instrumento que apontasse uma medida concreta para a força do impulso empresarial, ou seja, a intensidade motivadora de um indivíduo para criar uma empresa, examinando, 
justamente, se as diferenças na potência desse movimento afetam o desempenho do empreendimento.

De acordo com a escala CEI e com o resultado do teste, o indivíduo é classificado, a partir do seu potencial empreendedor, medido pelo número de pontos obtidos, em: (a) microempreendedores (0 a 15 pontos da escala) - percebem a organização como mais um aspecto de sua vida e cujo principal propósito é proporcionar autoemprego e renda suficiente para ter liberdade e usufruí-la com a família e os amigos; (b) empreendedores (16 a 25 pontos da escala) - possuem sonhos de riqueza, de liberdade e de reconhecimento por parte da sociedade; e (c) macroempreendedores (26 a 33 pontos da escala) - desejam tornar seu empreendimento líder no setor, valorizando o reconhecimento social e a riqueza, em detrimento do tempo livre e de aspectos familiares (Culti-Gimenez et al., 2006).

O instrumento considera quatro construtos: (1) traços de personalidade (TP) refere-se à necessidade de realização (NR) e à criatividade. Culti-Gimenez et al. (2006) definem essa dimensão como uma motivação social, pois o indivíduo com elevada necessidade de realização, busca atividades complexas, visa ao atingimento de metas difíceis, com altos níveis de desempenho, e se esforça para alcançar a excelência; (2) propensão à inovação (PI) - segundo Freitas, Ribeiro, Barbosa e Patrício (2009), é a dimensão que busca compreender se o empreendedor agrega inovação aos seus empreendimentos; (3) propensão ao risco (PR) - relaciona-se com os desafios enfrentados na busca dos objetivos, sendo também considerada pertinente ao empreendedor, assim como a PI. Para CultiGimenez et al. (2006, p. 3), tal dimensão pode ser entendida como "a tendência e desejo do indivíduo em aceitar ou evitar situações de incerteza relativa a uma situação em que os resultados podem ser negativos ou positivos"; e (4) postura estratégica (PE) - que mede a capacidade de percepção do indivíduo em relação aos negócios, bem como a exploração de oportunidades (Carland \& Carland, 1996).

Ressalta-se que o instrumento proposto não visa identificar quem é ou não empreendedor, mas posicionar o indivíduo dentro de um continuum de pessoas mais ou menos empreendedoras (Inácio Júnior \& Gimenez, 2004). Desse modo, todos os indivíduos são dotados de aspectos empreendedores, sendo o nível de intensidade e de aproveitamento dessas características o que os diferencia. Ademais, por abarcarem a personalidade e a postura, que são atributos subjetivos, pode-se concluir que não existe um único ou melhor instrumento para isso.

Rev. de Empreendedorismo e Gest. Pequenas Empres. | São Paulo, v.9 | n.3 | p. 272-302 | Maio/Ago. 2020. 


\section{METODOLOGIA}

A pesquisa fez a abordagem quantitativa dos dados, por meio de uma survey; e a abordagem qualitativa, no que diz respeito à análise documental dos planos de ensino das disciplinas ministradas no curso de Administração de uma IES privada. Quanto aos fins, ela é descritiva, visto que busca analisar o potencial empreendedor dos alunos, segundo o modelo CEI. Trata-se, por conseguinte, de um estudo quantitativo com aporte qualitativo.

Martins e Theóphilo (2016, p. 107) definem pesquisas quantitativas como "aquelas em que os dados e as evidências coletadas podem ser quantificados, mensurados e submetidos a técnicas e/ou testes estatísticos". De acordo com Marconi e Lakatos (2017), ao ancorar-se em regras da lógica, a pesquisa quantitativa permite clareza e controle das variáveis, excluindo a subjetividade e a inferência por parte do pesquisador, visto que seus resultados são verificados pela análise estatística.

Dentre as instituições privadas que ofertam cursos de Administração em Sobral, na região norte do Ceará, optou-se por aquela com o maior número de alunos - uma população de 230 discentes. Embora inserida em um dos maiores municípios da região, e considerada uma das maiores instituições de ensino, seu público, especificamente o pesquisado, apresenta um perfil socioeconômico concomitante em renda, de até dois salários mínimos (IBGE, 2010), oriunda do setor de serviços, seguido pela indústria. O questionário foi aplicado a 171 alunos presentes em sala de aula, no momento da realização da pesquisa, sendo o retorno de $87,72 \%$, pois foram excluídos 21 questionários, com preenchimento incompleto, restando 150 válidos.

Visando identificar quais disciplinas do curso possuíam foco em empreendedorismo e/ou abordavam essa temática, e para categorizar as estratégias de ensino comuns utilizadas, foi realizada uma pesquisa documental, em um universo de 46 planos de ensino, resultando em uma amostra de 17 planos selecionados e analisados.

Para identificar o perfil dos alunos e classificar seu potencial empreendedor, segundo a escala CEI, foi aplicado o instrumento elaborado por Carland et al. (1992), traduzido e validado no Brasil por Inácio Júnior e Gimenez (2004). Nesta pesquisa, contudo, ele foi dividido em dois blocos: o primeiro buscava informações 
para traçar o perfil dos estudantes, contendo perguntas de cunho relativo à faixa etária, ao gênero, à atividade profissional e à intenção de empreender; e o segundo seguia as questões do instrumento de Carland et al. (1992), que, como foi dito anteriormente, conta com 33 pares de questões para mensurar o potencial empreendedor, a partir de quatro dimensões.

Os dados quantitativos foram obtidos pela aplicação do instrumento CEl, tabulados de acordo com o recomendado por Inácio Júnior e Gimenez (2004), e analisados por meio de testes estatísticos, executados pelo software Statistical Package for the Social Sciences (SPSS), versão 20, que proporcionou a elaboração de tabelas e a posterior análise descritiva. Ressalta-se que, ao descrever uma amostra, o pesquisador tem íntimo contato com os dados obtidos, sendo possível, por conseguinte, antecipar-se aos problemas e identificar soluções prévias (Malhotra, 2006).

Conforme a escolha dos respondentes, em relação às questões objetivas, e a consequente soma de resultados, os indivíduos foram classificados, na escala $\mathrm{CEI}$, em: microempreendedores ( 0 a 15 pontos), empreendedores (16 a 25 pontos) e macroempreendedores (26 a 33 pontos).

\section{DISCUSSÃO DE RESULTADOS}

Nesta seção, serão apresentados os resultados da pesquisa, obtidos pela análise dos planos de ensino e pela aplicação dos questionários (que envolveu, por sua vez, as análises estatística, descritiva, média, de frequência, de desvio-padrão e de coeficiente de variação da amostra), além das estratégias de ensino, adotadas pelas disciplinas do curso.

\section{1 ESTRATÉGIAS DE ENSINO}

Os planos de ensino das disciplinas de todos os semestres do curso foram analisados, com fins de identificar quais continham conteúdos relacionados às temáticas do empreendedorismo, para categorizar as metodologias/estratégias de ensino utilizadas em sala de aula.

Na IES estudada, 17 disciplinas abordam essa temática, contribuindo para uma formação empreendedora. Em Jogos Empresariais, por exemplo, a estratégia de ensino envolve a simulação de uma empresa, realizada por um software, pela qual os alunos assumem o papel de donos de um negócio, competindo em equipes, com 
o objetivo o alcançar o sucesso do empreendimento. Além disso, a disciplina inclui materiais e ferramentas de aprendizagem para desenvolver 0 potencial empreendedor dos alunos, como: contato com empresários, apresentação de pitches de negócios, participação em eventos, entre outros.

Embora as disciplinas apresentem abordagens e estratégias distintas, adotadas pelos professores, algumas são comuns à maioria delas, como: a aula expositiva, a apresentação de seminários, o estudo de caso, as leituras, as discussões de artigos/textos, os exercícios e os jogos.

Esse resultado corrobora: (a) o estudo de Guimarães (2002), que também destacou as aulas expositivas e as leituras, necessárias para munir o aluno de informações sobre os processos de criação de empresas, bem como desenvolver valores e atitudes essenciais à prática empresarial; (b) a pesquisa de Vieira et al. (2013), que apontou para uma alta incidência de aulas expositivas (em 98\% dos casos), de aplicação de estudos de caso (em 94\%), e a realização de trabalhos teóricos em grupo (92\%); e (c) o trabalho de Greatti et al. (2010), que preconiza os exercícios e os jogos de simulação como estratégia, haja vista a necessidade de o empreendedorismo priorizar, em sala de aula, "metodologias problematizadoras", que levam o aluno a refletir sobre a solução de problemas, por meio da experimentação e do relacionamento prático-teórico.

A propósito do empreendedorismo em sala de aula, os resultados desta pesquisa vão ao encontro do estudo de Vieira et al. (2013), que indica 57,04\% de aulas teóricas e práticas; $27,41 \%$ somente de aulas teóricas; e 2,22\% apenas de aulas práticas, nos cursos de Administração.

A prática, portanto, é fator inerente ao aprendizado do empreendedorismo, uma vez que a vivência, a adaptação, a experimentação e a inserção em contextos reais fornecem ao aluno a projeção de um ambiente propício ao desenvolvimento de sua formação empreendedora, no qual ele aprende fazendo (Filion, 2000; Souza et al., 2004; Lavieri, 2010; Lopes, 2010, Lima et al., 2015a, 2015b; Rocha \& Freitas, 2014; Machado et al., 2018; Hashimoto \& Fonseca Jr., 2018; Hashimoto et al., 2018).

Todas essas estratégias e abordagens, identificadas nas disciplinas cujos conteúdos tratam da temática "empreendedorismo", são coerentes com os resultados alcançados por esta pesquisa. Assim, as principais atividades educacionais de formação em empreendedorismo (AEFE) são: aulas expositivas; 
visitas e contatos com empresas; plano de negócios; estudos de casos; trabalhos teóricos e práticos (individuais e em grupo); grupos de discussão; seminários e palestras; criação de empresa, produtos, filmes e vídeos; e jogos de empresas/simulações.

\subsection{CLASSIFICAÇÃO DO POTENCIAL EMPREENDEDOR}

Com fins de identificar o perfil dos discentes estudados, foram considerados os seguintes aspectos: gênero, faixa etária, semestre do curso, se exerce ou não atividade remunerada, e se possui intenção de abrir negócio próprio.

$\mathrm{Na}$ amostra analisada, maioria é formada por homens $(62,67 \%)$, na faixa etária de 20 a 24 anos (47,33\%), cursando até a metade do curso (semestres 1 a 4 $62,7 \%$ ), sendo que 68,67\% declararam exercer alguma atividade remunerada. Apenas 10\% possuem empresa; e, dentre os que não possuem (135 indivíduos), 115 afirmaram ter intenção de empreender (76,75\%). Quando questionados sobre a que atribuíam a sua intenção empreendedora, 44,5\% citaram o ensino universitário; $33,6 \%$, o convívio familiar; e $21,8 \%$, o convívio com amigos. Esses resultados coadunam parcialmente com os encontrados na pesquisa GEM (2018), na qual a maioria é masculina (51,3\%), de jovens adultos (18 a 24 anos), pertencentes ao grupo de empreendedores iniciais $(22,2 \%)$.

Como já foi dito anteriormente, este estudo adotou o modelo teórico $\mathrm{CEI}$, para a classificação do potencial empreendedor dos respondentes, que considera quatro dimensões de características: postura estratégica (PE), propensão à inovação (PI), traços de personalidade (TP) e propensão ao risco (PR).

Segundo Carland e Carland (1996), a postura estratégica (PE) observa como o indivíduo utiliza a percepção e a intuição para a solução de problemas. Nesse sentido, as características verificadas dizem respeito ao quanto ele é capaz de perceber oportunidades, tomar decisões, negociar e fazer com que as ações aconteçam em uma economia em movimento. Na sequência, estão os resultados investigados por esta pesquisa, em relação a esse construto (Tabela 1). 
Tabela 1

Mapa das características empreendedoras dos respondentes - Postura Estratégica (PE)

\begin{tabular}{l|c|c|c|c|c}
\hline \multirow{2}{*}{ Construto } & \multirow{2}{*}{$\begin{array}{c}\text { Questões } \\
\text { CEI }\end{array}$} & \multicolumn{2}{|c|}{$\begin{array}{c}\text { Respostas SEM } \\
\text { Características }\end{array}$} & \multicolumn{2}{c}{$\begin{array}{c}\text { Respostas COM } \\
\text { Características }\end{array}$} \\
\cline { 3 - 6 } & 1 & Frequência & \% & Frequência & \% \\
\hline Postura Estratégica & 4 & 56 & 37,30 & 94 & 62,70 \\
Postura Estratégica & 13 & 8,70 & 137 & 91,30 \\
Postura Estratégica & 5 & 44 & 29,30 & 106 & 70,70 \\
Postura Estratégica & 8 & 13 & 8,70 & 137 & 91,30 \\
Postura Estratégica & 9 & 89 & 59,30 & 61 & 40,70 \\
Postura Estratégica & 11 & 55 & 36,70 & 95 & 63,30 \\
Postura Estratégica & 12 & 37 & 24,70 & 113 & 75,30 \\
Postura Estratégica & 20 & 48 & 32,00 & 102 & 68,00 \\
Postura Estratégica & 21 & 118 & 78,70 & 32 & 21,30 \\
Postura Estratégica & 23 & 42 & 28,00 & 108 & 72,00 \\
Postura Estratégica & 24 & 66 & 44,00 & 84 & 56,00 \\
Postura Estratégica & 27 & 57 & 38,00 & 93 & 62,00 \\
Postura Estratégica & 28 & 84 & 56,00 & 66 & 44,00 \\
\hline
\end{tabular}

Fonte: Dados da pesquisa (2020).

Ocupando a primeira posição no ranking, estão as respostas à Questão 4, "eu gostaria que este negócio crescesse e se tornasse uma empresa forte", e à Questão 8, "um plano deveria ser escrito para ser efetivo", ambas com 91,3\% de frequência. $\mathrm{Na}$ segunda posição, com 75,3\% de frequência, está a resposta à Questão 12, "eu seria aquele que tem de pensar e planejar" (Tabela 1). Esses resultados reafirmam os achados de Penz, Amorim, Nascimento e Silveira (2014) e de Tormen, Nascimento, Verdinelli e Lizote (2015), visto que, em suas pesquisas, as Questões 4 e 8 também aparecem entre as três primeiras colocações.

Entre as respostas sem características empreendedoras, relativas ao construto PE, destaca-se a dada à Questão 21, "nada sobre gerenciar um negócio é sempre rotina", com 78,7\%, que ocupa o primeiro lugar. A segunda posição é ocupada pela resposta à Questão 9, "eu dividiria meu tempo entre este negócio, família e amigos", com 59,3\% de frequência (Tabela 1). Esses resultados corroboram igualmente os achados de Penz et al. (2014) e de Tormen et al. (2015).

Para Culti-Gimenez et al. (2006), a dimensão propensão à inovação (PI) é considerada fundamental ao ato de empreender e ao reconhecimento de oportunidades, no que diz respeito à criatividade e à melhoria do negócio como um todo. Freitas et al. (2009) afirmam que a PI investiga a incorporação de aspectos 
inovadores às ações empreendedoras. A seguir, estão as características empreendedoras relacionadas a esse construto, obtidas por este estudo (Tabela 2).

Tabela 2

Mapa das características empreendedoras dos respondentes - Propensão à Inovação (PI)

\begin{tabular}{l|c|c|c|c|c}
\hline \multirow{2}{*}{ Construto } & \multirow{2}{*}{$\begin{array}{c}\text { Questões } \\
\text { CEI }\end{array}$} & \multicolumn{2}{|c|}{$\begin{array}{c}\text { Respostas SEM } \\
\text { Características }\end{array}$} & \multicolumn{2}{c}{$\begin{array}{c}\text { Respostas COM } \\
\text { Características }\end{array}$} \\
\cline { 3 - 6 } & & Frequência & \% & Frequência & \% \\
\hline Propensão à Inovação & 17 & 64 & 42,70 & 86 & 57,30 \\
Propensão à Inovação & 19 & 67 & 44,70 & 83 & 55,30 \\
Propensão à Inovação & 22 & 105 & 70,00 & 45 & 30,00 \\
Propensão à Inovação & 25 & 46 & 30,70 & 104 & 69,30 \\
Propensão à Inovação & 33 & 45 & 30,00 & 105 & 70,00 \\
\hline
\end{tabular}

Fonte: Dados da pesquisa (2020).

Entre as respostas com características empreendedoras, a dada à Questão 33, "é mais importante ver possibilidades nas situações", destaca-se, com frequência de $70 \%$ dos respondentes. O segundo lugar é ocupado pela resposta à Questão 25, "eu adoro a ideia de tentar ser mais esperto que os concorrentes", com $69,30 \%$ dos indivíduos da amostra (Tabela 2).

Entre as respostas sem características empreendedoras, a dada à Questão 22, "eu prefiro pessoas que são realistas", teve maior frequência (70\%), seguida pelas dadas às Questões 19, "eu penso que procedimentos operacionais padrões são cruciais", e 17, "eu procuro estabelecer procedimentos padrões para que as coisas sejam feitas certas", cujo alcance foi de 19,44\% e 17,42\%, respectivamente (Tabela 2). Esses resultados confirmam os achados de Tormen et al. (2015) e corroboram parcialmente os de Penz et al. (2014).

No que tange ao construto traços de personalidade (TP), também denominado necessidade de realização, Culti-Gimenez et al. (2006) o consideram uma motivação social, pois o indivíduo com elevada necessidade de realização demonstra a preferência por tarefas difíceis e metas ousadas, que exigem esforço contínuo para manter elevado o padrão de desempenho. A seguir, estão as características empreendedoras relacionadas a esse construto, obtidas por este estudo (Tabela 3). 
Tabela 3

Mapa das características empreendedoras dos respondentes - Traços de Personalidade (TP)

\begin{tabular}{|c|c|c|c|c|c|}
\hline \multirow[t]{2}{*}{ Construto } & \multirow{2}{*}{$\begin{array}{l}\text { Questões } \\
\text { CEI }\end{array}$} & \multicolumn{2}{|c|}{$\begin{array}{l}\text { Respostas SEM } \\
\text { Características }\end{array}$} & \multicolumn{2}{|c|}{$\begin{array}{c}\text { Respostas COM } \\
\text { Características }\end{array}$} \\
\hline & & Frequência & $\%$ & Frequência & $\%$ \\
\hline Traços de Personalidade & 2 & 62 & 41,30 & 88 & 58,70 \\
\hline Traços de Personalidade & 3 & 86 & 57,30 & 64 & 42,70 \\
\hline Traços de Personalidade & 6 & 68 & 45,30 & 82 & 54,70 \\
\hline Traços de Personalidade & 7 & 25 & 16,70 & 125 & 83,30 \\
\hline Traços de Personalidade & 10 & 44 & 29,30 & 106 & 70,70 \\
\hline Traços de Personalidade & 13 & 116 & 77,30 & 34 & 22,70 \\
\hline Traços de Personalidade & 14 & 82 & 54,70 & 68 & 45,30 \\
\hline Traços de Personalidade & 15 & 87 & 58,00 & 63 & 42,00 \\
\hline Traços de Personalidade & 16 & 51 & 34,00 & 99 & 66,00 \\
\hline Traços de Personalidade & 18 & 91 & 60,70 & 59 & 39,30 \\
\hline Traços de Personalidade & 29 & 75 & 50,00 & 75 & 50,00 \\
\hline Traços de Personalidade & 32 & 71 & 47,30 & 79 & 52,70 \\
\hline
\end{tabular}

Fonte: Dados da pesquisa (2020).

Entre as respostas com características empreendedoras, a dada à Questão 7, "eu não descansaria até que nós fossemos os melhores", ocupa o primeiro lugar, com 83,3\% de frequência. Em segundo lugar, está a resposta à Questão 10, "eu tendo a deixar minha cabeça governar meu coração", com 70,7\% (Tabela 3). Esses resultados obtidos corroboram parcialmente os estudos de Penz et al. (2014) e de Tormen et al. (2015).

Entre as respostas sem característica empreendedoras, a primeira posição é ocupada pela dada à Questão 13, "as pessoas que trabalhassem para mim, gostariam de mim", com 77,3\%, seguida das respostas às Questões 18, "eu penso que é importante ser otimista", e 3, "eu não iniciaria este negócio se eu não tivesse certeza de que seria bem-sucedido", com $60,7 \%$ e $57,3 \%$ de frequência, respectivamente (Tabela 3). Esses resultados corroboram parcialmente os achados de Tormen et al. (2015), que obtiveram maiores respostas às Questões 3, 13 e 15. Por outro lado, com relação ao trabalho de Penz et al. (2014), a convergência de resultados está apenas na resposta à Questão 13, que ocupa o terceiro lugar na pesquisa dos autores. Por fim, a escala CEI apresenta o construto propensão ao risco (PR) que, para Freitas et al. (2009), é uma dimensão associada à possibilidade de um evento não ocorrer conforme o planejado. Essa característica é considerada como inerente ao empreendedor, visto que conceber e gerir um empreendimento é, por si só, uma atividade arriscada. Nesse sentido, a PR investiga uma maior 
propensão de ousar ou arriscar. A seguir, estão as características empreendedoras relacionadas a esse construto, obtidas por este estudo (Tabela 4).

\section{Tabela 4}

Mapa das características empreendedoras dos respondentes - Propensão ao Risco (PR)

\begin{tabular}{l|c|c|c|c|c}
\hline \multirow{2}{*}{ Construto } & \multirow{2}{*}{$\begin{array}{c}\text { Questões } \\
\text { CEI }\end{array}$} & \multicolumn{2}{c|}{$\begin{array}{c}\text { Respostas SEM } \\
\text { Características }\end{array}$} & \multicolumn{2}{c}{$\begin{array}{c}\text { Respostas COM } \\
\text { Características }\end{array}$} \\
\cline { 3 - 6 } & & Frequência & \% & Frequência & \% \\
\hline Propensão ao Risco & 26 & 57 & 38,00 & 93 & 62,00 \\
Propensão ao Risco & 30 & 12 & 8,00 & 138 & 92,00 \\
Propensão ao Risco & 31 & 50 & 33,30 & 100 & 66,70 \\
\hline
\end{tabular}

Fonte: Dados da pesquisa (2020).

Acerca das características empreendedoras, verifica-se que o primeiro lugar é ocupado pela resposta à Questão 30, "se você que quer um negócio cresça, você tem que assumir alguns riscos", com 92\% de frequência, seguida pela dada à Questão 31, "eu realmente não sentiria falta de trabalhar para alguém", com 66,7\% (Tabela 4). Esses resultados corroboram parcialmente os achados de Penz et al. (2014) e de Tormen et al. (2015), visto que, em ambos, a resposta à Questão 30 ocupou o primeiro lugar entre os seus entrevistados.

No que diz respeito às respostas sem características empreendedoras, a dada à Questão 26, "a melhor abordagem é evitar o risco tanto quanto possível”, está em primeiro lugar, com 38\% de frequência. O segundo lugar, com 33,3\%, pertence à resposta à Questão 31, "a coisa que eu mais sentiria falta em trabalhar para alguém seria a segurança" (Tabela 4). Esses resultados corroboram parcialmente os encontrados por Penz et al. (2014) e Tormen et al. (2015), pois, em ambos, a resposta à Questão 31 ocupa posição entre o primeiro e o segundo lugar, na escolha dos respondentes.

Quanto aos resultados da amostra no CEI, os indivíduos apresentam potencial empreendedor médio de 19,73 pontos, o que os coloca acima da média teórica da escala (16,5), com desvio-padrão de 3,51, mediana 20, e moda 19. A distribuição desses resultados apresentou valor mínimo de 11 pontos e máximo de 30 pontos, sendo que, ao distribuir os respondentes nas três classificações da escala, obtevese: (a) 127 empreendedores (84,67\%), (b) 16 microempreendedores (10,67\%), e (c) 7 macroempreendedores (4,67\%).

Constata-se que a aplicação da escala CEI junto aos estudantes, além de revelar o perfil empreendedor dos discentes, também corrobora parcialmente os 
estudos de Inácio Junior e Gimenez (2004), Culti-Gimenez et al. (2006), Penz et al. (2014) e Tormen et al. (2015).

Uma vez analisado o potencial empreendedor dos respondentes, buscou-se estabelecer as relações entre as variáveis, com a finalidade de identificar se alguma característica do perfil do indivíduo propicia determinado potencial empreendedor. Para tanto, foi utilizada a técnica estatística de análise de variância (Anova) que, de acordo com Hair, Black, Babin, Anderson e Tatham (2009, p. 304), tem o objetivo de "determinar se as amostras de dois ou mais grupos surgem de populações com médias iguais". Sendo assim, o que se busca é identificar se as médias dos grupos diferem significativamente. O potencial empreendedor foi estabelecido, então, como variável dependente, sendo as variáveis independentes: gênero, idade, semestre do curso, ter ocupação, possuir empresa, ter intenção de abrir empresa e participar de oficinas ofertadas pela IES.

Considerando o valor de "p" como 5\%, as características de perfil anteriormente listadas foram individualmente analisadas. Constatou-se que os resultados obtidos não apresentaram diferenças estatísticas entre os três níveis de potencial empreendedor dos respondentes. Dessa forma, não é possível afirmar que as características de perfil analisadas e a participação em oficinas de formação, oferecidas pela IES, apresentam influência sobre o potencial empreendedor dos indivíduos inqueridos na pesquisa (Tabela 5).

\section{Tabela 5}

Anova para características de perfil x potencial empreendedor

\begin{tabular}{lccccc}
\hline \multicolumn{1}{c}{ Caracteristica } & $\begin{array}{c}\text { Soma dos } \\
\text { Quadrados }\end{array}$ & df & $\begin{array}{c}\text { Média dos } \\
\text { Quadrados }\end{array}$ & F & Sig. \\
\hline Gênero & 32,35 & 1 & 32,35 & 2,66 & 0,105 \\
Idade & 118,91 & 6 & 19,82 & 1,66 & 0,136 \\
Semestre & 141,19 & 7 & 20,17 & 1,69 & 0,115 \\
Trabalha/Não & 1,36 & 1 & 1,36 & 0,11 & 0,741 \\
$\begin{array}{l}\text { Possui empresa } \\
\text { Intenção abrir }\end{array}$ & 1,93 & 1 & 1,93 & 0,16 & 0,694 \\
$\begin{array}{l}\text { empresa } \\
\text { Participação em } \\
\text { oficinas }\end{array}$ & 20,48 & 2 & 10,24 & 0,83 & 0,438 \\
\end{tabular}

Fonte: Dados da pesquisa (2020). 
Após a conclusão das análises dos dados oriundos da pesquisa, o capítulo a seguir versa sobre as considerações finais deste estudo.

\section{CONSIDERAÇÕES FINAIS}

Partindo do modelo teórico proposto por Carland et al. (1992), este estudo investigou a contribuição do ensino de empreendedorismo para o desenvolvimento do potencial empreendedor de estudantes de uma IES privada do Ceará. Para tanto, os planos de ensino das disciplinas de todos os semestres do curso foram analisados, a fim de identificar quais delas continham algum conteúdo que abordasse as temáticas de empreendedorismo, para, assim, categorizar as estratégias de ensino utilizadas no trabalho em sala de aula.

Foram identificadas 17 disciplinas com conteúdo relacionado à formação empreendedora, que utilizam diversas metodologias de ensino, com destaque para: aulas expositivas, apresentação de seminário, estudo de caso, leituras e discussões de artigos/textos, exercícios e jogos.

Com relação aos construtos medidos pelo $\mathrm{CEI}$, constatou-se a presença das quatro dimensões propostas pelos autores: postura estratégica (PE), propensão ao risco $(\mathrm{PR})$, traços de personalidade (TP) e propensão à inovação $(\mathrm{PI})$, sendo que esses achados corroboram os resultados alcançados por Penz et al. (2014) e Tormen et al. (2015).

No que diz respeito à classificação do potencial empreendedor, conforme o CEI, houve predominância de indivíduos classificados como empreendedores $(84,66 \%)$. Segundo o referencial teórico, esses indivíduos, ao empreenderem, buscam lucratividade e evolução do seu empreendimento. No entanto, por estarem na faixa intermediária da escala, seu comportamento é de difícil previsibilidade.

A segunda classificação de potencial empreendedor mais encontrada foi a de microempreendedores, com 10,67\% da amostra. Em seus empreendimentos, esses indivíduos buscam o autoemprego, a qualidade de vida, além do sustento pessoal e familiar.

Os macroempreendedores, por sua vez, constituíram 4,67\% da amostra. Os indivíduos enquadrados nesse nível da escala CEI se caracterizam pela busca do primeiro lugar na atuação no mercado, devido à sua postura inovadora e criativa, que os faz desejar recompensas sociais e financeiras, em virtude da realização de seu empreendimento. 
A análise de variância (Anova) foi realizada para identificar se alguma característica do perfil do indivíduo propiciava determinado potencial empreendedor. No entanto, com um "p" de 5\%, os resultados obtidos não apresentaram diferenças estatísticas entre os três níveis de potencial empreendedor dos respondentes, indicando normalidade entre os dados, ou seja, não foi possível afirmar que as características de perfil analisadas exercem influência nos resultados do potencial empreendedor encontrados por este estudo.

Os resultados da pesquisa demonstram que a metodologia de trabalho dos docentes das disciplinas que abordam temáticas de empreendedorismo necessita de um grau de empenho maior do que o papel tradicional de professor universitário, apontando como desejável a preconização de metodologias ativas. Isso se dá porque o aluno precisa aprender fazendo, por meio da experimentação, da reflexão e da prática, o que pode despertar seu potencial empreendedor. Essa percepção é confirmada pela atribuição, da maioria dos alunos, da origem de sua intenção empreendedora estar no ensino universitário. Por isso, o envolvimento pedagógico deve ser diferenciado nesse processo de ensino-aprendizagem, a fim de estabelecer uma coerência maior ao papel que o empreendedor desempenha na sociedade.

Para ensinar empreendedorismo, é fundamental ter experiência, dinamismo e preparo, visto que o campo é complexo e tem diversas peculiaridades. E para aprender, deve-se ter pré-disposição para participar das atividades acadêmicas. Sendo assim, o docente, para estimular o aluno, precisa estar cada vez mais preparado e atento ao tipo de público que tem em sala de aula, para escolher adequadamente a metodologia/técnica a ser utilizada.

Quanto à IES pesquisada, foi possível perceber a oferta de disciplinas, conteúdos e abordagens que favorecem o desenvolvimento do potencial empreendedor; no entanto, há a necessidade de maior contato dos alunos com experiências, vivências práticas e exemplos, além da interação com empreendedores, visto que são poucas as disciplinas que contemplam essas ações. Acredita-se que, dessa forma, a academia possa contribuir para uma melhor formação e desenvolvimento do potencial de seu corpo discente.

Em relação às IES brasileiras, em geral, é essencial que elas disponham de estruturas facilitadoras e aceleradoras do processo de formação do potencial empreendedor e, consequentemente, do desenvolvimento econômico, haja vista que 
tanto o empreendedorismo quanto o indivíduo empreendedor exercem função de mola propulsora da economia. Para tanto, o papel do Estado, nos âmbitos social e econômico deve ser cumprido, pois, mesmo que o empreendedor seja um agente social capaz de desenvolver a economia local/regional, sozinho ele não conseguirá solucionar todos os problemas circundantes.

No que concerne às limitações deste estudo, destaca-se o fato de que, em virtude da aplicação dos questionários ter ocorrido próxima ao período de avaliação da segunda etapa do semestre, muitos discentes não estavam em sala de aula ou dispostos a responder à pesquisa com veracidade, resultando em 21 formulários expurgados da amostra, por estarem incompletos ou incorretamente preenchidos, 0 que representou $12,28 \%$ de um total de 171.

Outro aspecto relevante é que o potencial empreendedor foi medido por um instrumento fechado e de autopreenchimento, que não leva em consideração bagagens anteriores dos indivíduos pesquisados. A aplicação de técnicas adicionais, como entrevistas com os participantes, serviria de comparação entre o CEI e o discurso dos indivíduos.

Por fim, cabe ressaltar como limitação o fato de que as frequências de potencial empreendedor (127), microempreendedor (16) e macroempreendedor (7), são muito diferentes entre si. Caso a análise de variância (Anova) fosse realizada com frequências similares, ela proporcionaria resultados mais confiáveis ao estudo.

Sugere-se, para pesquisas futuras: (a) a triangulação entre as visões do professor, do aluno e da coordenação de curso; (b) a análise das intenções empreendedoras dos alunos que mencionarem o desejo de abrir seu próprio negócio; e (c) a realização de um estudo longitudinal, com fins de medir o potencial empreendedor e o mapeamento das competências empreendedoras desses alunos, após a conclusão da graduação.

\section{REFERÊNCIAS}

Andreassi, T., \& Fernandes, R. J. R. (2010). O uso das competições de planos de negócios como ferramenta de ensino de empreendedorismo. In Lopes, R. M. A. (Org.). Educação empreendedora: conceitos, modelos e práticas. Rio de Janeiro: Elsevier; São Paulo: Sebrae. 
Bernheim, C. T., \& Chauí, M. de S. (2008). A universidade e a sociedade do conhecimento. Desafios da universidade na sociedade do conhecimento. Brasília: Unesco.

Boyles, T. (2012). 21st century knowledge, skills, and abilities and entrepreneurial competence: a model for undergraduate entrepreneurship education. Journal of Entrepreneurship Education, 15, 41-55.

Carland, J. W., \& Carland, J. A. (1996). The Theoretical Bases and Dimensionality of the Carland Entrepreneurship Index. Proceedings of the RISE 96 Conference, University of Jyvaskylâ, Finlândia.

Carland, J. W., Carland J. A., \& Hoy, F. (1992). An entrepreneurship Index: an empirical validation. Frontiers of Entrepreneurship Research, 25(3), 244-265.

Carland, J. W., Carland, J. A. \& Hoy, F. (1998). Who is an Entrepreneur? Is a question worth asking? American Journal of Small Business, 15(3), 33-39.

Carree, M. A., \& Thurik, A. R. (2003). The Impact of Entrepreneurship on Economic Growth. In Acs, Z. J., \& Audretsch, D. B. Handbook of Entrepreneurship Research: An Interdisciplinary Survey and Introduction. Great Britain: Kluwer Academic Publishers.

Culti-Gimenez, S., Costa, M. I., Schypula, A., \& Gimenez, F. A. P. (2006). Comportamento empreendedor de alunos do curso de turismo. Cadernos da Escola de Negócios, 1(4), 28-40.

Degen, R. (2009). O empreendedor: empreender como opção de carreira. São Paulo: Pearson Prentice Hall.

Drucker, P. F. (1986). Inovação e espírito empreendedor. São Paulo: Pioneira.

Ferreira, A. C., Alcântara, V. C., \& Freitas, F. M. (2013). Adaptação, validação e discussões da aplicação de uma escala de medida do potencial empreendedor em universitários. $R P C A, 7(3), 115-138$.

Filion, L. J. (2000). Empreendedorismo: Ciência, Técnica e Arte. Brasília: CNI IEL Nacional. 
Fonseca, R. S, J.; Hashimoto, M. (2014). A importância do ensino empreendedor na formação de Nível Técnico. In: VIII Encontro de Estudos em Empreendedorismo e Gestão de Pequenas Empresas, 8., Goiânia, 2014. Anais... São Paulo: ANEGEPE.

Franco, M. A. S. (2015). Práticas pedagógicas de ensinar-aprender: por entre resistências e resignações. Educação \& Pesquisa, 41(3), 601-614.

Freitas, A. A. F., Ribeiro, R. C. L., Barbosa, R. T., \& Patrício, P. E. A. (2009). O potencial empreendedor de empreendedores informais clientes de programas de microcrédito: uma avaliação sob as perspectivas de capital humano e gênero. Anais do Encontro Nacional da Associação Nacional de Pós-Graduação e Pesquisa em Administração, São Paulo, SP, 33.

Gartner, W. B. (1989). Who is an entrepreneur? Is the wrong question. Entrepreneurship Theory and Practice, 13(1), 47-68.

GEM Brasil (2018). Empreendedorismo no Brasil. Relatório Executivo. Disponível em:< https://datasebrae.com.br/wp-content/uploads/2019/02/Relat\%C3\%B3rio-ExecutivoBrasil-2018-v3-web.pdf $\geq$. Acesso em: 26 maio 2020.

Greatti, L., Gralik, E., Vieira, F. G. D., \& Sela, V. M. (2010). Aprendizagem em Empreendedorismo dos Acadêmicos do Curso de Administração de uma Universidade Estadual no Sul do Brasil. Anais do Encontro Nacional da Associação Nacional de PósGraduação e Pesquisa em Administração. Rio de Janeiro, RJ, 34.

Guimarães, L. O. (2002). A experiência universitária norte-americana na formação de empreendedores. Contribuições das universidades de Saint Louis, Indiana e Babson College (Tese de Doutorado). Fundação Getúlio Vargas, Escola de Administração de Empresas, São Paulo, SP, Brasil.

Hair, J. F., Black, W. C., Babin, B. J., Anderson, R. E., \& Tatham, R. L. (2009). Análise Multivariada de Dados (6a. ed.). Porto Alegre: Bookman.

Hashimoto, M., \& Fonseca Jr. R. S. (2018). A Importância do Ensino Empreendedor na Formação de Nível Técnico. Revista de Negócios, 23(3), 7-18. 
Hashimoto, M., Krakauer, P. V. de C., \& Cardoso, A. M. (2018). Inovações nas técnicas pedagógicas para a formação de empreendedores. RPCA, 12(4), 17-38.

Hecke, A. P. (2011). A intenção empreendedora dos alunos concluintes dos cursos de Graduação em Administração e Ciências Contábeis das Instituições de Ensino Superior de Curitiba (Dissertação de Mestrado). Faculdade de Administração e Ciências Contábeis, Universidade Federal do Paraná. Curitiba, PR, Brasil.

Henrique, D. C., \& Cunha, S. K. da. (2008). Práticas didático-pedagógicas no ensino de empreendedorismo em cursos de graduação e pós-graduação nacionais e internacionais. Revista de Administração Mackenzie (RAM), 9(5), 112-136.

Hisrich, R., Peters, M., \& Shepherd, D. (2014) Empreendedorismo (9a ed.). Porto Alegre: Bookman.

Honig, B. (2004). Entrepreneurship education: toward a model of contingency-based business planning. Academy of Management Learning and Education, 3(3), 258-273.

IBGE. Censo Demográfico 2010. Disponível em: < http://www.cidades.ibge.gov.br/xtras/perfil.php?lang=\&codmun=231290\&search=ceara|sobra |linfograficos:-informacoes-completas> Acesso em: 26 jul. 2016.

llander, G. P-B. (2010). The use of feature films to promote entrepreneurship. International Journal Information and Operation Management Education, 3(3), 284-302.

Inácio Júnior, E., \& Gimenez, F. A. P. (2004). Potencial Empreendedor: um instrumento para a mensuração. Revista de Negócios, 9(2), 107-116.

Johan, D. A., Krüger C., \& Minello, I. F. (2018). Educação empreendedora: um estudo bibliométrico sobre a produção científica recente. Navus, 8(4), 125-145.

Knotts, T. L. (2011). The SBDC in the classroom: providing experiential learning opportunities at different entrepreneurial stages. Journal of Entrepreneurship Education, 14, 25-38. 
Kuratko, D. F. (2005). The emergence of entrepreneurship education: development, trends, and challenges. Entrepreneurship Theory and Practice, 29(5), 577-598.

Lavieri, C. (2010) Educação... empreendedora? In Lopes, R. M. A. (Org.). Educação empreendedora: conceitos, modelos e práticas. Rio de Janeiro: Elsevier; São Paulo: Sebrae.

Lima, E., Hashimoto, M., Melhado, J., \& Rocha, R. (2014). Caminhos para uma Melhor Educação Superior em Empreendedorismo no Brasil. Anais do Encontro da ANPAD, Rio de Janeiro, RJ, 38.

Lima, E., Lopes, R. M. A., Nassif, V. M. J., \& Silva, D. (2015a). Opportunities to Improve Entrepreneurship Education: Contributions Considering Brazilian Challenges. Journal of Small Business Management, https://onlinelibrary.wiley.com/doi/abs/10.1111/jsbm.12110> Acesso em: 25 maio 2020.

Lima, E., Lopes, R. M. A., Nassif, V. M. J., \& Silva, D. (2015b). Ser seu Próprio Patrão? Aperfeiçoando-se a Educação Superior em Empreendedorismo. RAC, 19(4), 419-439.

Lopes, R. M. A. (2010). Educação empreendedora: conceitos, modelos e práticas. São Paulo: Sebrae; Rio de Janeiro: Elsevier.

Machado, A. C. A., Lenzi, F. C., \& Manthey, N. B. (2017). O Ensino do Empreendedorismo em Cursos de Graduação: Panorama das Práticas dos Cursos de Ciências Sociais Aplicadas. Revista Alcance, 24(4), 554-573.

Malhotra, N. (2006). Pesquisa de marketing: uma orientação aplicada (4a. ed.). Porto Alegre: Bookman.

Marconi, M. de A., \& Lakatos, E. M. (2017). Metodologia Científica (7a. ed.). São Paulo: Atlas.

Martins, G. de A., \& Theóphilo, C. R. (2016). Metodologia da Investigação Científica para Ciências Sociais Aplicadas (3a. ed.). São Paulo: Atlas. 
McClelland, D. C. (1972). A sociedade competitiva: realização e progresso social. Rio de Janeiro: Editora Expressão e Cultura.

Mintzberg, H.; Quinn, J. B. (2001). O processo da estratégia. Porto Alegre: Bookman.

Neck, H. M., \& Greene, P. G. (2011). Entrepreneurship Education: Known Worlds and New Frontiers. Journal of Small Business Management, 49(1), 55-70.

Neck, H. M., Greene, P. G., \& Brush, C. G. (2015). Teaching entrepreneurship as a method that requires practice. In Teaching Entrepreneurship: A Practice-Based Approach. New York: Edward Elgar Publishing.

Nunes, C. P. \& Oliveira, D. A. (2017). Trabalho, carreira, desenvolvimento docente e mudança na prática educativa. Educação \& Pesquisa, 43(1), 66-80.

Penz, D., Amorim, B. C., Nascimento, S., \& Silveira, A. (2014). Potencial empreendedor dos discentes do curso de administração de uma instituição privada à luz do Carland Entrepreneurship Index (CEI). Anais do Encontro de Estudos em Empreendedorismo e Gestão de Pequenas Empresas. Goiânia, GO, 8.

Ribeiro, P. E., \& Bernardes, M. A. (2014). O Papel da Universidade no Desenvolvimento do Comportamento Empreendedor em Regiões Carentes. Revista Eletrônica Gestão e Serviços, 5(2), 978-993.

Rocha, E. L. de C., \& Freitas, A. A. F. (2014). Avaliação do Ensino de Empreendedorismo entre Estudantes Universitários por meio do Perfil Empreendedor. Revista de Administração Contemporânea RAC, 18(4), 465-486.

Santos, P. C. F. (2008). Uma escala para identificar potencial empreendedor. 2008. Tese (Doutorado em Engenharia de Produção) - Universidade Federal de Santa Catarina, Florianópolis.

Santos, S. C., Caetano, A., \& Curral, L. (2010). Atitude dos estudantes universitários face ao empreendedorismo. Revista Portuguesa e Brasileira de Gestão, 9(4), 2-14. 
Schmidt, J. S., Soper J. C., \& Facca, T. M. (2012). Creativity in the entrepreneurship classroom. Journal of Entrepreneurship Education, 15, 23-131.

Schumpeter, J. A. (1934). Teoria do Desenvolvimento Econômico: uma investigação sobre lucros, capital, crédito, juro e o ciclo econômico. São Paulo: Abril Cultural.

Silva, G. S. da. (2010). Educação Empreendedora nas IES Cearenses: Um estudo Multicaso (Dissertação de Mestrado). Universidade de Fortaleza, Fortaleza, CE, Brasil.

Souza, E. C. L. de., Souza, C. C. L. de., Assis, S. de A. G., \& Zerbini, T. (2004). Métodos e técnicas de ensino e recursos didáticos para o ensino do empreendedorismo em IES brasileiras. Anais do Encontro Nacional da Associação Nacional de Pós-Graduação e Pesquisa em Administração, Rio de Janeiro, RJ, 28.

Souza, M. J. B., Trindade, F. de M., Freire, R., \& Lyra, F. R. (2016). Potencial empreendedor de empresárias do setor turístico de Florianópolis (SC). Revista Alcance, 23(4), 455-474.

Timmons, J. A. (1989). The Entrepreneurial Mind. Andover. Massachussetts: Brick House Publishing Company.

Tormen, J., Nascimento, S. do., Verdinelli, M. A., \& Lizote, S. A. (2015). Potencial Empreendedor dos Estudantes das Ciências Sociais Aplicadas de uma Instituição de Ensino Superior sob a Ótica do Carland Entrepreneurship Index (CEI). Revista ADMPG, 8(2), 17-25.

Veit, M. R., \& Gonçalves Filho, C. (2007). Mensuração do Perfil Empreendedor e seu impacto no desempenho das pequenas empresas. Anais do Encontro da ANPAD, Rio de Janeiro, RJ, 31.

Vieira, S. F. A.; Melatti, G. A.; Oguido, W. S.; Pelisson, C.; Negreiros, L. F. (2013). Ensino de empreendedorismo em Cursos de Administração: um levantamento da realidade brasileira. Revista de Administração FACES Journal, v. 12, n. 2, p. 93-114. 